\title{
Strength and Compressibility Characteristics of Fiber-Reinforced Subgrade and their Effects on Response of Granular Fill-Subgrade System
}

\author{
Kousik Deb $^{1} \cdot$ Yogesh Kumar Narnaware ${ }^{1}$
}

Received: 16 September 2015/ Accepted: 17 November 2015/Published online: 9 December 2015

(C) Springer International Publishing Switzerland 2015

\begin{abstract}
In the present study, strength as well as compressibility characteristics of fiber-reinforced clay are studied. Synthetic fibers with different lengths $(3,6$ and $12 \mathrm{~mm})$ and different quantities $(0.25,0.5,1$ and $1.5 \%$ by weight) are added with clay. Strength characteristics are studied by conducting unconfined compressive strength test and compressibility characteristics are studied by conducting oedometer tests on unreinforced as well as fiberreinforced clay. All the samples are prepared at optimum moisture content to achieve maximum dry density. Based on the obtained experimental results, the effect of fiber reinforcement on settlement response of granular fill-fiberreinforced subgrade system has been studied. The granular fill (representing subbase or base) is modelled by Pasternak Shear layer. The improved and unimproved sub-grade is modeled as nonlinear springs with different stiffness (modulus of subgrade reaction). The governing differential equations of the model are solved by finite difference scheme in an iterative manner and the results are presented in non dimensional form. It is observed that unconfined compressive strength of the clay increases due to addition of fiber. In terms of strength, $0.5-1 \%$ fiber is observed as optimum quantity for the selected soil. It is also observed that compression index of the clay decreases due to the addition of fiber which indicates the reduction of consolidation settlement of the soil. The coefficient of consolidation of the soil increases due to the addition of fiber
\end{abstract}

Kousik Deb

kousik@civil.iitkgp.ernet.in

Yogesh Kumar Narnaware

ynarnaware@gmail.com

1 Department of Civil Engineering, Indian Institute of Technology Kharagpur, Kharagpur 721302, India which indicates that rate of consolidation of the soil increase due to the addition of fiber. It is further observed that settlement of the granular fill-subgrade system decreases at a decreasing rate as the thickness of the fiberreinforced zone increases. Significant improvement of the settlement due to the increase in thickness of the fiberreinforced subgrade zone is not observed during the initial stage of consolidation. However, as the degree of consolidation (or time) increases more settlement improvement is observed due to the increase in the thickness of the fiberimproved subgrade zone i.e. the effectiveness of the use of fiber reinforcement increases as the degree of consolidation increases. Thus, to get significant amount of settlement improvement due to increase in thickness of the fiber-reinforced clay, sufficient amount of consolidation settlement should be occurred.

Keywords Compressibility - Consolidation . Fiber-reinforced subgrade $\cdot$ Settlement $\cdot$ Strength

\section{Introduction}

Stabilization of soft subgrade is an economic solution for construction of pavement. Studies show that stabilizing the weak subgrade with fiber increases its strength. The performance of the pavement improves when the weak subgrade is stabilized with fiber. The increase in load carrying capacity and reduction in rut depth, cost and construction time are observed due to the stabilization of subgrade with fiber reinforcement. Most of the available studies on stabilization of clay with randomly distributed fibers are concentrated on strength improvement characteristics [15]. Few studies are also conducted on compressibility characteristics of fiber-reinforced clay $[6,7]$. Studies show 
that consolidation settlement of the clay decreases due to the addition of fiber. It has been also observed that Compression Index of clay decreases as the fiber amount increases up to a certain percentage of fiber and after that it starts increasing again. The Coefficient of Consolidation also increases as fiber amount increases [7]. Thus, it has been observed that use of fiber in clay not only increases the strength of the soil, but also increases the rate of consolidation of the clay. It also decreases the Compression Index of the clay which indicates the reduction of consolidation settlement of the soil.

Studies are also conducted on fiber-reinforced granular fill-soft soil or soft subgrade system. Yetimoglu et al. [8] studied the bearing capacity of randomly distributed fiberreinforced sand fills overlying soft clay. Chandra et al. [9] investigated the benefits of reinforcing the subgrade soils with fiber in flexible pavements. Kumar and Singh [10] used reinforced fly ash as subbase material in rural roads. Deb et al. [11-13] developed mechanical models to study the response of multi layer geosynthetic-reinforced granular fill resting on soft soil. Thus, it has been observed that most of the studies on fiber-reinforced clay are conducted to observe the strength and compressibility characteristics of the improved clay only. Very limited studies are conducted to study the effect of fiber on response of granular fill-soft subgrade system. Even in the available studies on granular fill-soft soil system, granular fill or base or subbase is reinforced with fibers or geosynthetic reinforcements (in most of the available models on granular fill-soft subgrade system). Again, very limited work has been conducted to study the consolidation behaviour of granular fill-fiber-improved subgrade system. In the present study, strength and compressibility characteristics of fiber-reinforced clay are studied based on unconfined compression strength test and oedometer test, respectively. To study the response of granular fill-fiber-improved soft subgrade system, a mechanical model has been used based on the obtained experimental results. Effects of both strength and consolidation characteristics of fiber-reinforced subgrade on the settlement response have been studied.

\section{Experimental Study}

\section{Materials and Preparation of Samples}

In the present study, strength and compressibility characteristics of the fiber-reinforced clay are determined by unconfined compression strength tests and oedometer tests, respectively. The grain size distribution curve and the properties of the clay used in the present study are shown in Fig. 1 and Table 1, respectively. Synthetic fibers with different lengths (3, 6 and $12 \mathrm{~mm})$ and different quantities

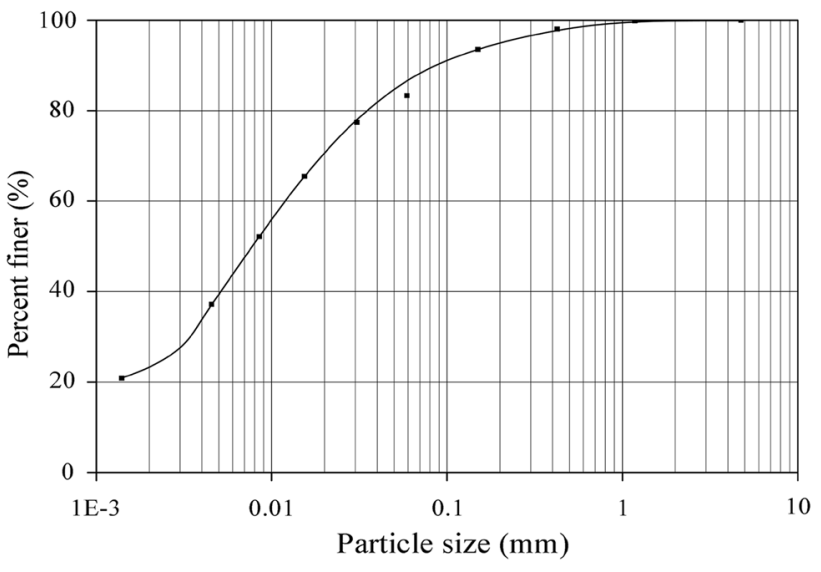

Fig. 1 Grain size distribution curve of clay

Table 1 Properties of the soil material

\begin{tabular}{ll}
\hline Properties & Values \\
\hline Specific gravity & 2.41 \\
Liquid limit (\%) & 44 \\
Plastic limit (\%) & 26 \\
Plasticity index & 18 \\
Maximum dry unit weight $\left(\mathrm{kN} / \mathrm{m}^{3}\right)$ & 17.1 \\
Optimum moisture content $(\%)$ & 17.6 \\
Bulk unit weight at OMC $\left(\mathrm{kN} / \mathrm{m}^{3}\right)$ & 20.1 \\
USCS classification & $\mathrm{CL}$ \\
\hline
\end{tabular}

$(0.25,0.5,1$ and $1.5 \%$ by dry weight $)$ are added with clay to show the effect of length and quantity of fiber on strength and compressibility characteristics of the fiberreinforced clay.

The volume of soil sample for unconfined compression strength tests or oedometer tests was calculated. The weight of clay required to prepare the sample was calculated by multiplying the volume with unit weight of the clay sample. Water at optimum moisture content of unreinforced clay i.e. $17.6 \%$ of dry weight of clay was weighed (for both unreinforced and reinforced clay) and kept in small beaker. The weight of fibre as percentage of dry weight of clay was calculated for a particular percentage (say $0.25 \%$ of dry weight of clay). The weighed ovendried clay was placed on a tray and spread to form a thin layer. The weighed amount of water was poured uniformly over the clay. The weighed amount of fibres was then spread uniformly by hand. All three were mixed manually for some time to achieve a uniform mix. Finally, the mixture was placed in respective moulds, compacted and used for experimentations. As far as checks for uniform mixing of fibres are concerned, no standard checks were conducted except visual inspection of the mixture/sample. 
Visual inspection included discarding samples with excessive local fibre concentration in sample, non-uniform moisture distribution etc.

\section{Unconfined Compression Strength Tests}

Unconfined compression strength test specimens were prepared with $38 \mathrm{~mm}$ diameter and $76 \mathrm{~mm}$ height. The samples were prepared at optimum moisture content to achieve maximum dry unit weight. The tests were conducted on unreinforced and fiber-reinforced soils with different fiber contents and fiber lengths. Number of tests was conducted for each percentage (or length) of fiberreinforced and unreinforced clay. Typical stress-strain curves for unreinforced and reinforced soils are shown in Figs. 2 and 3 for different fiber contents. Figure 2 shows the stress-strain curves for $12 \mathrm{~mm}$ fiber length with different percentage of fibers. Figure 3 shows the stress-strain curves with $1.5 \%$ fibers for different fiber lengths. From the obtained results, the values of modulus of elasticity and ultimate stresses are determined. It is observed that the obtained stress-strain curves of both unimproved and fiberreinforced soils are nonlinear in nature. Thus, the modulus of elasticity is calculated corresponding to the initial tangent to the stress-strain curves [9]. The strain level in the initial tangent portion of the stress-strain curve (elastic range) is shown in Fig. 2 and Fig. 3.

Figure 4 shows the variation of unconfined compression strength (UCS) with different fiber contents and lengths. From unconfined compression strength characteristics it is observed that for 3 and $6 \mathrm{~mm}$ fiber, $0.5 \%$ is the optimum fiber content to be used for the selected soil and for $12 \mathrm{~mm}$ fiber length the optimum fiber content is $1 \%$. Thus, $0.5-1 \%$ fiber content is the optimum value depending on the length of the fiber. The values of modulus of elasticity

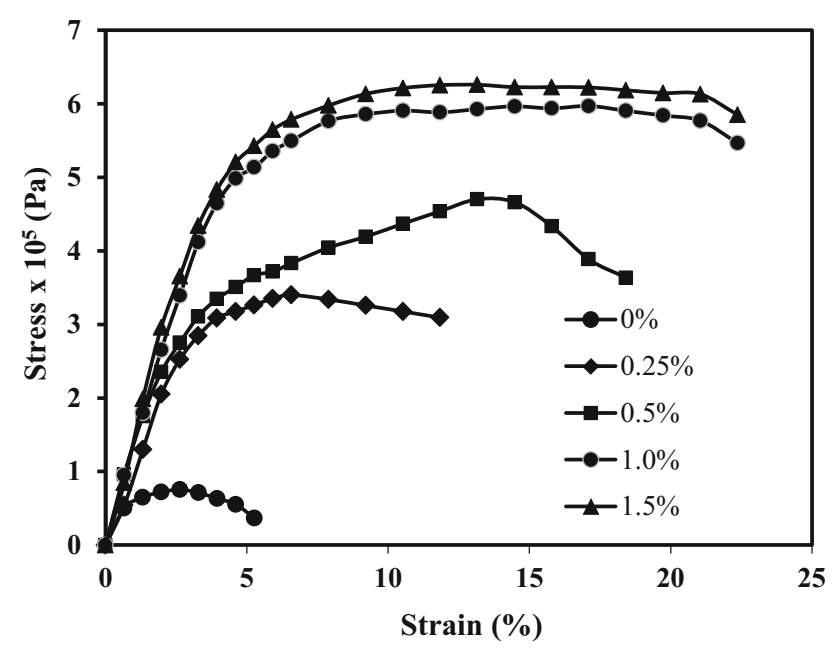

Fig. 2 Stress-strain diagrams of $12 \mathrm{~mm}$ fiber

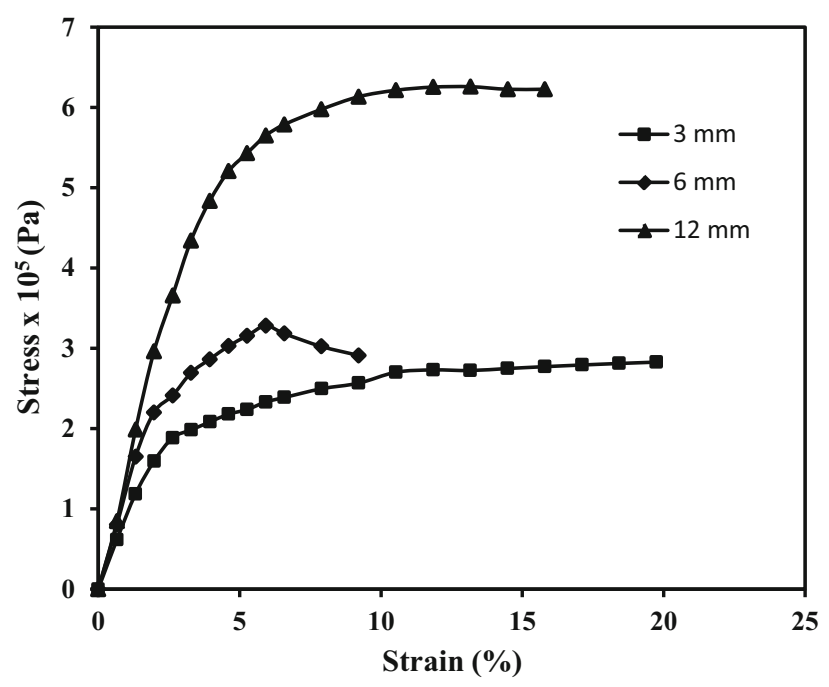

Fig. 3 Stress-strain diagrams of $1.5 \%$ fiber

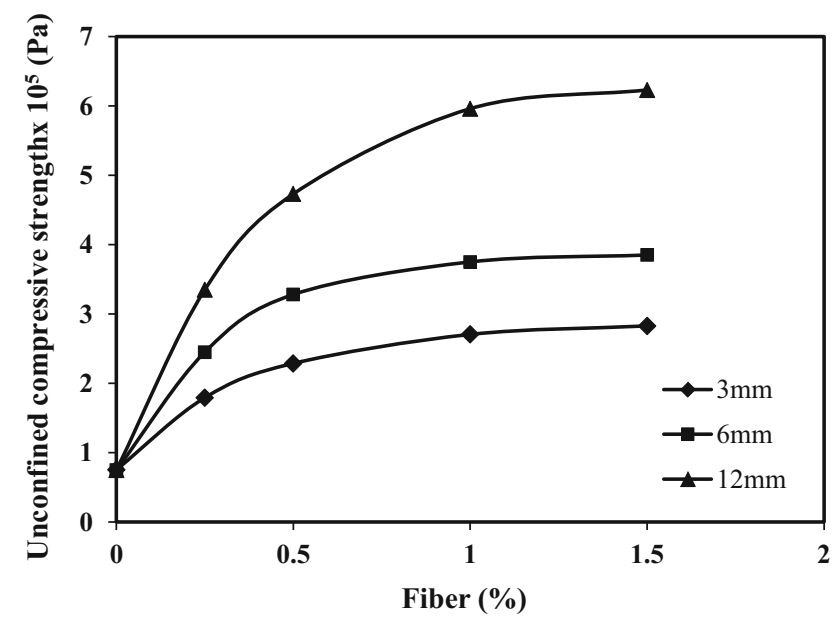

Fig. 4 Effect of fiber on unconfined compressive strength

$E$, unconfined compression strength obtained for unreinforced and fiber-reinforced soils are presented in Table 2 for different fiber contents and lengths. It is observed that as the fiber content and length increase the $E$ value and UCS value increase. However, the rate of increment of UCS value is more as compared to the rate of increment of $E$ value. The increment of UCS value from unimproved soil to fiber-reinforced soil with $1 \% 12 \mathrm{~mm}$ fiber is almost 7 times, whereas the increment is $91 \%$ in case of $E$ value.

\section{Oedometer Test}

The oedometer tests were conducted on unreinforced and fiber-reinforced soil with $60 \mathrm{~mm}$ diameter and $20 \mathrm{~mm}$ thick samples to determine the consolidation properties. Figures 5 and 6 show the effect of fiber on Compression Index and Coefficient of Consolidation of the unreinforced 
Table 2 Modulus of elasticity and UCS values

\begin{tabular}{llllcc}
\hline Sl. no. & Length $(\mathrm{mm})$ & $\%$ of fiber & $E(\mathrm{MPa})$ & UCS $(\mathrm{kPa})$ & $c_{u}(\mathrm{kPa})$ \\
\hline 1 & - & 0 & 7.6 & 75 & 37.5 \\
2 & 12 & 0.25 & 11.5 & 335 & 167.5 \\
3 & 12 & 0.50 & 13.3 & 473 & 236.5 \\
4 & 12 & 1.00 & 14.5 & 596 & 298.0 \\
5 & 12 & 1.50 & 15.1 & 623 & 311.5 \\
6 & 6 & 1.50 & 12.5 & 385 & 192.5 \\
7 & 3 & 1.50 & 9.0 & 283 & 141.5 \\
\hline
\end{tabular}

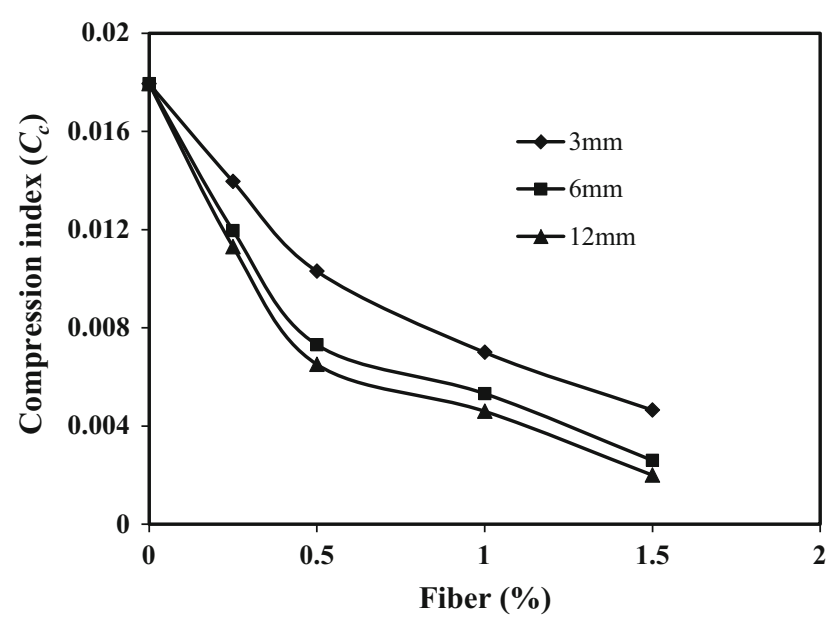

Fig. 5 Effect of fiber on compression index

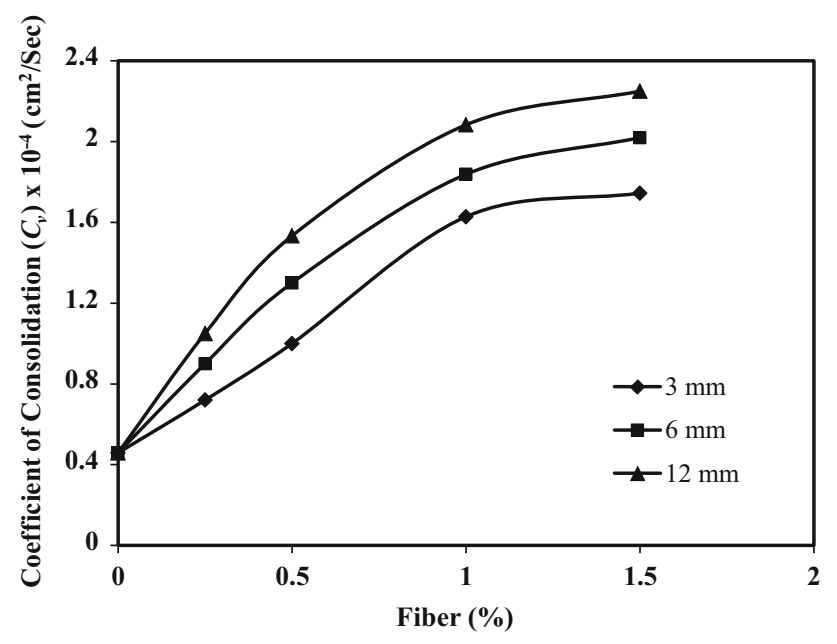

Fig. 6 Effect of fiber on coefficient of consolidation

and reinforced soils, respectively. It is observed that as the fiber content increases Compression Index also decreases and Coefficient of Consolidation increases. However, Coefficient of Consolidation increases up to $1 \%$ fiber content and beyond that value of it becomes constant. Thus, as expected the strength of the soil increases as the fiber is added. The rate of consolidation increases (up to
$1 \%$ fiber) and consolidation settlement decreases due to addition of fibers. Thus, $1 \%$ fiber can be considered as optimum value to increase the rate of consolidation. Compression index will still decrease due to the addition of fiber, but from the analytical study it is observed that beyond $0.5 \%$ fiber not much settlement reduction is observed for the selected soil (Fig. 10). Thus, 0.5-1\% fiber content is the optimum value with respect to settlement reduction and rate of consolidation increment. All the results are obtained by conducing tests on only soil type. Thus, it is required to use the obtained results to study the response of improved as well as unimproved subgrade system. A mechanical model can be proposed to idealize the pavement system based on two-parameter model to study the response of granular fill-soft subgrade system. The model is capable to determine the settlement of the granular fill-soft subgrade system for different fiber contents and lengths. The effect of thickness of the improved subgrade zone on settlement response can also be studied. The effect of consolidation of improved and unimproved subgrade on settlement response can also be studied by the developed model.

\section{Model Development}

Figure 7 shows a granular fill-soft subgrade system. The granular fill is representing the base or subbase and idealized by Pasternak Shear layer. Two or more granular layers with different properties can be incorporated in the model. Similarly, base and sub-base layers can be incorporated in the model by idealizing with Pasternak Shear layers with different properties. Subgrade is idealized with nonlinear springs. Nonlinear shear stress and shear strain behaviour is considered for granular layer to idealize the proper stress and strain behaviour of soil. Similarly, nonlinear stress and strain relationship is considered to model the subgrade soil. The improved subgrade is idealized with stiffer springs or stiffer material as compared to the unimproved subgrade. Plain-strain condition has been considered in the analysis. Similar type of model was adopted for single layer geosynthetic-reinforced granular fill [14-16] and multilayered reinforced granular fill $[11-13,17]$ resting on soft 
Fig. 7 Granular fill-fiberreinforced soft sub-grade system

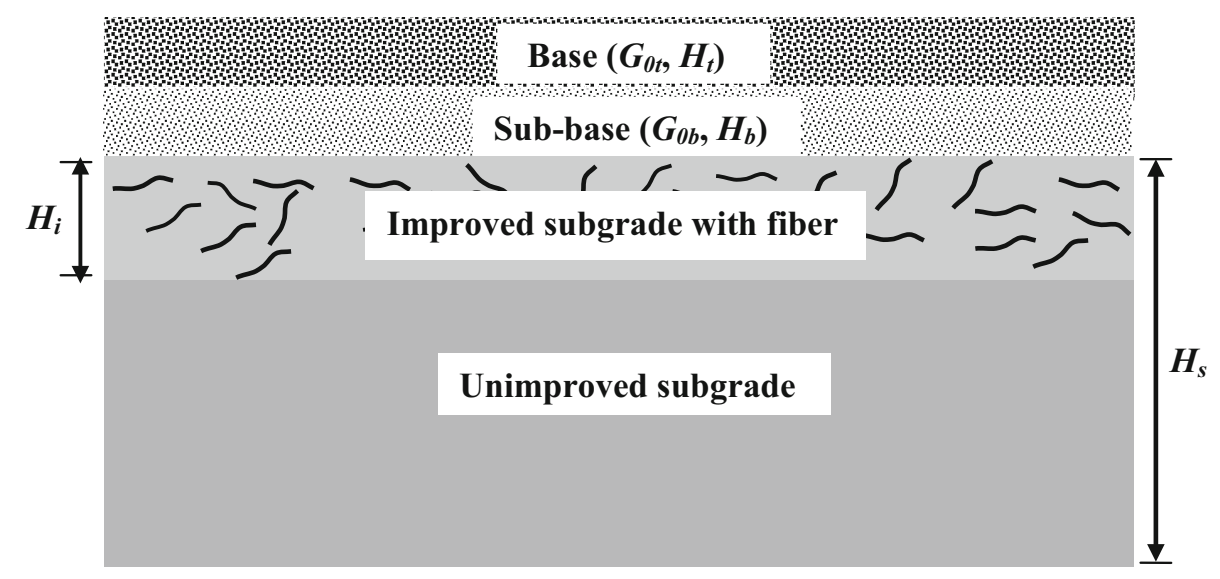

soil. Rajesh et al. [18] developed similar type of model for geosynthetic reinforced railway tracks resting on soft clays. Based on the Pasternak Shear layer concept, the governing differential equation of the presented model can be written as [19]:

$q=\frac{k_{s 0} w}{U\left[1+k_{s 0}\left(w / q_{u}\right)\right]}-\left(G_{t} H_{t}+G_{b} H_{b}\right) \frac{\partial^{2} w}{\partial x^{2}}$

where $q$ is the vertical stress acting on the surface; $H_{t}$ and $H_{b}$ are the thickness of the top granular layer (base) and bottom granular layer (subbase) placed over the soft subgrade, respectively; $w(x, t)$ is the vertical displacement or settlement; $\partial w(x, t) / \partial x$ is the shear strain and $G_{t}$ and $G_{b}$ are the shear modulus of the top and bottom granular layer, respective and can be expressed by considering the hyperbolic shear stress-shear strain response proposed by Ghosh and Madhav [20] as:

$G_{t}=\frac{G_{0 t}}{\left[1+\frac{G_{0 t}|\partial w / \partial x|}{\tau_{u t}}\right]^{2}} \quad$ and $\quad G_{b}=\frac{G_{0 b}}{\left[1+\frac{G_{0 b}|\partial w / \partial x|}{\tau_{u b}}\right]^{2}}$

where $G_{0}$ is the initial shear modulus of the shear layer(s); $\tau_{u}$ is the ultimate shear resistance of the granular layer(s). $k_{s 0}$ and $q_{u}$ are initial modulus of subgrade reaction and the ultimate bearing capacity of the saturated soft subgrade, respectively. The initial shear modulus can be determined by taking the slope of the initial straight portion of the stress versus strain curve of the granular material (base or sub-base materials). Ultimate shear resistance is the ultimate stress value obtained from the stress versus strain curve. Similarly, initial modulus of subgrade reaction and the ultimate bearing capacity of the saturated soft subgrade are the slope of the initial straight portion and ultimate stress of the stress versus displacement curve of the subgrade material. The ultimate load carrying capacity of the improved and unimproved subgrade can also be determined based on the determined soil properties ( $c_{u}$ value). Based on the unconfined compressive strength value, the initial modulus of subgrade reaction of the ground can be determined from the available range. The initial shear modulus value can also be determined from the available range for different granular materials. $U$ is the degree of consolidation of the subgrade soil. Using the non dimensional parameters as: $X=x / B ; \quad W=w / B ; G_{t}^{*}=G_{t} H_{t} \prime$ $k_{s 0} B^{2} ; G_{b}^{*}=G_{b} H_{b} / k_{s 0} B^{2} ; G_{0 t}^{*}=G_{t 0} H_{t} / k_{s 0} B^{2} ; G_{0 b}^{*}=G_{b 0} H_{b} /$ $k_{s 0} B^{2} ; \quad q^{*}=q / k_{s 0} B ; \quad q_{u}^{*}=q_{u} / k_{s 0} B ; \quad \tau_{u t}^{*}=\tau_{u t} H_{t} / k_{s 0} B^{2} ;$ $\tau_{u b}^{*}=\tau_{u b} H_{b} / k_{s 0} B^{2}$; where $B$ is the half width of the loaded region applied on the surface as traffic loading. The governing differential equation at time $t>0$ can be written in non dimensional form as:

$q^{*}=\frac{W}{U\left[1+\left(W / q_{u}^{*}\right)\right]}-\left(G_{t}^{*}+G_{b}^{*}\right) \frac{\partial^{2} W}{\partial X^{2}}$

A computer program based on the above formulation has been developed and solutions are obtained. Parametric studies have been carried out to show the effects of various parameters on the settlement response. Finite difference method has been employed to solve the governing differential equation [Eq. (3)]. In the equation, the derivative has been expressed by central difference scheme. The length $L /$ $B$ is divided into ' $n$ ' number of elements with $(n+1)$ number of node points ( $\mathrm{i}=1,2,3,4$ to $\mathrm{n}$ ), where $L$ is the half domain of the problem. As the problem is symmetric, only half of the system is considered for the analysis. Thus at the centre of the loaded region $X=0$ ( or $x=0$ ), due to symmetry, the slope, $\partial W / \partial X$ will be zero. The width of the granular fill considered in the analysis is sufficiently enough that at the edge [at $X=L / B$ (or $x=L)$ ] the slope, $\partial W / \partial X$ of the settlement-distance profile will also be zero. The loading conditions are: $q_{i}^{*}(X)=q^{*}$ for $|X| \leq 1.0$ and $q_{i}^{*}(X)=0$ for $|X|>1.0$. The governing differential equation has been solved in an iterative method to determine the settlement of the granular-fill surgrade system at different points and the results are presented in non dimensional form. 
The model is capable to incorporate two or more granular layers with different thicknesses and shear modulus. However, in the present study, same soil properties are considered for two granular layers. To study the effect of fiber in settlement response, a uniformly distributed loading has been applied at the surface. The soil within the influence zone of the loaded region is considered in the study. The ultimate load carrying capacity of the improved and unimproved subgrade is calculated based on the determined soil properties $\left(c_{u}\right.$ value). However, in the laboratory tests soil strength properties were determined under undrained condition. Drained soil properties of soft subgrade can be determined based on the available relationships. The Poisson ratio of the subgrade is taken constant due to the addition of fibers. Thus, it can be written as: $k_{s o i} / k_{s \mathrm{o} u}=E_{i} / E_{u}$, where $E_{i}$ and $E_{u}$ are the Elastic modulus of improved and unimproved subgrade, respectively. Similarly, $k_{s o i}$ and $k_{s o u}$ are the initial subgrade reaction if improved and unimproved subgrade, respectively. During calculation of the initial subgrade reaction and ultimate load carrying capacity of the improved subgrade, weightage average has been taken depending upon the thickness of the improved zone $\left(H_{i}\right)$. The factor $T_{v}$ $\left(=c_{v} t / H_{s}^{2}\right)$ is calculated from the measured values of $c_{v}$ under single drainage condition. From the time factor, degree of consolidation is calculated for a particular time period $t$. During calculation of $c_{v}$ for improved subgrade, weightage average of different $c_{v}$ is considered depending upon the thickness of the improved subgrade layer. The initial shear modulus, ultimate shear resistance and thickness of the granular layer are taken as $15 \mathrm{MPa}, 100 \mathrm{kPa}$ and $0.3 \mathrm{~m}$, respectively. The non-dimensional parameters are calculated based on the given expression of different parameters. Based on the unconfined compressive strength value, the initial modulus of subgrade reaction of the unimproved ground is taken as $20,000 \mathrm{kN} / \mathrm{m}^{2} / \mathrm{m}$ (from the available range). The value of non-dimensional parameters varies due to the change in modulus of subgrade reaction for addition fiber of different percentage, length and thickness. For example, the equivalent subgrade modulus value for the clay improved with $1.5 \% 3 \mathrm{~mm}$ fiber up to $0.5 \mathrm{~m}$ depth is $21,084 \mathrm{kN} / \mathrm{m}^{2} / \mathrm{m}$. Thus, in the developed analytical model, the percentage value or length of fiber is not incorporated directly. However, change in soil properties due to the addition of fiber with different percentages and length is incorporated in the developed model to study the effect of fiber on consolidation settlement. The equivalent rectangular loaded area based on axle load and tire inflation pressure can be calculated from the study presented by Giroud and Noiray [21]. Charts are presented with axle load 80 and $130 \mathrm{kN}$ for on-highway trucks and 390,540 and $870 \mathrm{kN}$ for off-highway trucks against tire inflation pressure of 480 and $620 \mathrm{kPa}$. Thus, the range of dimension of the equivalent loaded area is $0.36 \times$ $0.25-0.52 \times 0.37 \mathrm{~m}$ for on-highway trucks and $0.94 \times$ $0.47-1.6 \times 0.80 \mathrm{~m}$ for off-highway trucks. However, the present study is under plain strain condition and a unit width of $1 \mathrm{~m}$ is considered with reduced tire pressure. The present study investigates the effect of fiber reinforcements on the response of granular-fill soft subgrade system. Thus, change of width and tire pressure may change the value of the settlement, but overall trend of the observation will remain same. The consolidation settlement can also be calculated using Terzaghi's 1-D consolidation theory. However, from the conventional consolidation theory, maximum settlement can be calculated due to the application of load, but in the present model settlement can be determined at different location within and beyond the loaded region. In the present developed model, during settlement calculation both strength and compressibility characteristics are considered. The properties of the granular layers (base or subbase) are also incorporated during the settlement calculation in the developed model.

Figures 8 and 9 show the effect of fiber percentage and length on settlement response, respectively at the end of consolidation (i.e. $U=100 \%$ ). It is observed that as the fiber percentage and length increase settlement response decreases. However, after $0.5 \%$ fiber not much settlement reduction is observed even for $12 \mathrm{~mm}$ fiber length. It is also observed that as the thickness of the improved subgrade increases maximum non-dimensional settlement (at the centre of the loaded region) also decreases in a decreasing rate. From the figures it can be observed that up to $H_{i} /$ $H_{s}=0.3$ (where $H_{i}$ is the thickness of the improved subgrade and $H_{s}$ is the total thickness of the subgrade with the influenced zone) the rate of reduction in settlement is more and after that it decreases. In case of $0.5 \% 12 \mathrm{~mm}$ fiber,

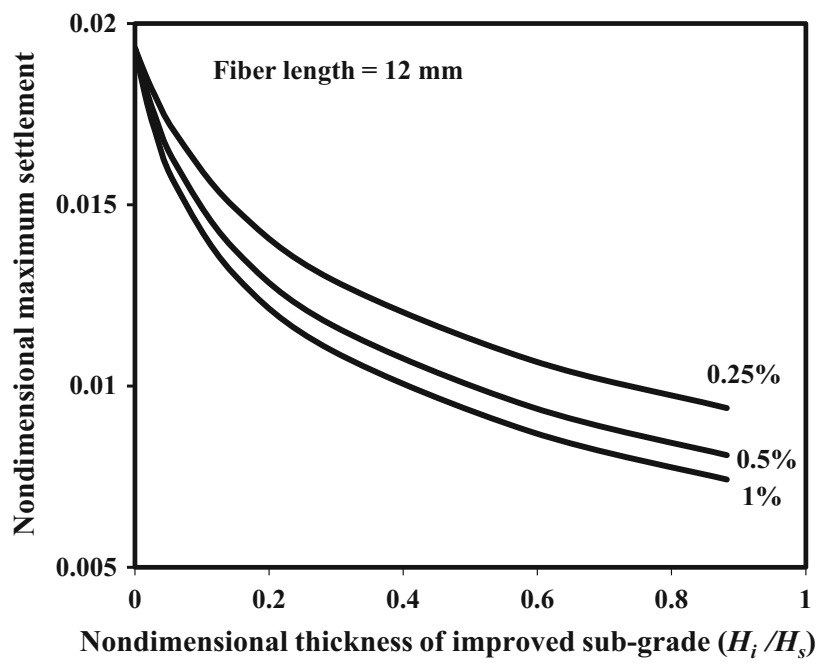

Fig. 8 Effect of fiber percentage on settlement response 


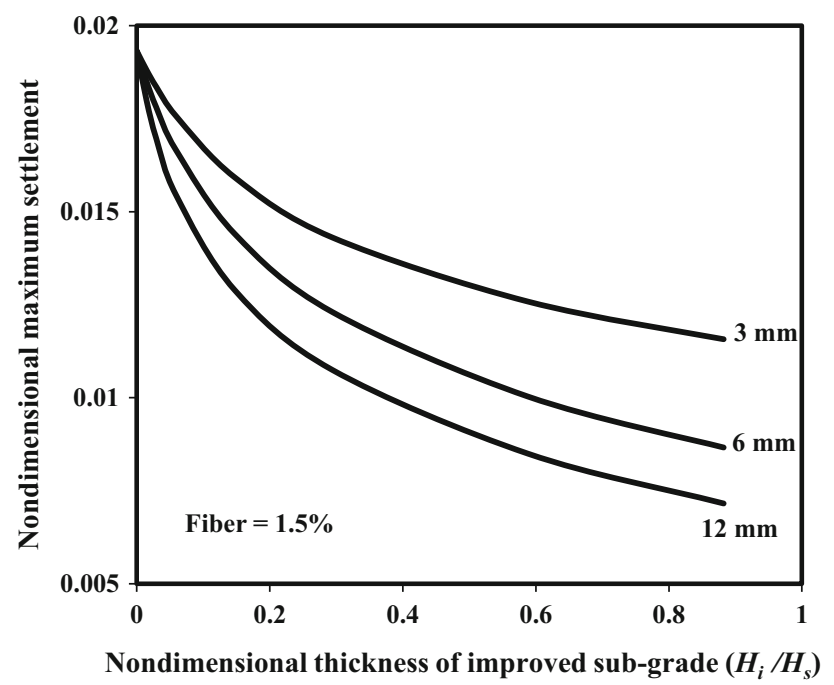

Fig. 9 Effect of fiber length on settlement response

the settlement reduction is $40 \%$ as $H_{i} / H_{s}$ value increases from 0 to 0.3 . However, as $H_{i} / H_{s}$ value increases from 0.3 to 0.8 further settlement reduction is $18 \%$. Whereas, in case of $1 \% 12 \mathrm{~mm}$ fiber, the settlement reduction is $43 \%$ as $H_{i} / H_{s}$ value increases from 0 to 0.3 . Thus, due to increment of fiber content from 0.5 to $1 \%$, additional only $3 \%$ settlement reduction is observed for $H_{i} / H_{s}=0.3$.

Figures 10 and 11 show the effect of time factor $\left(T_{v}\right)$ on settlement response for different fiber percentages and lengths, respectively. It is observed that for lower value of $T_{v}$ i.e. initial stage of consolidation, the variation of settlement for different fiber percentages and lengths is negligible. As the $T_{v}$ value increases the difference between

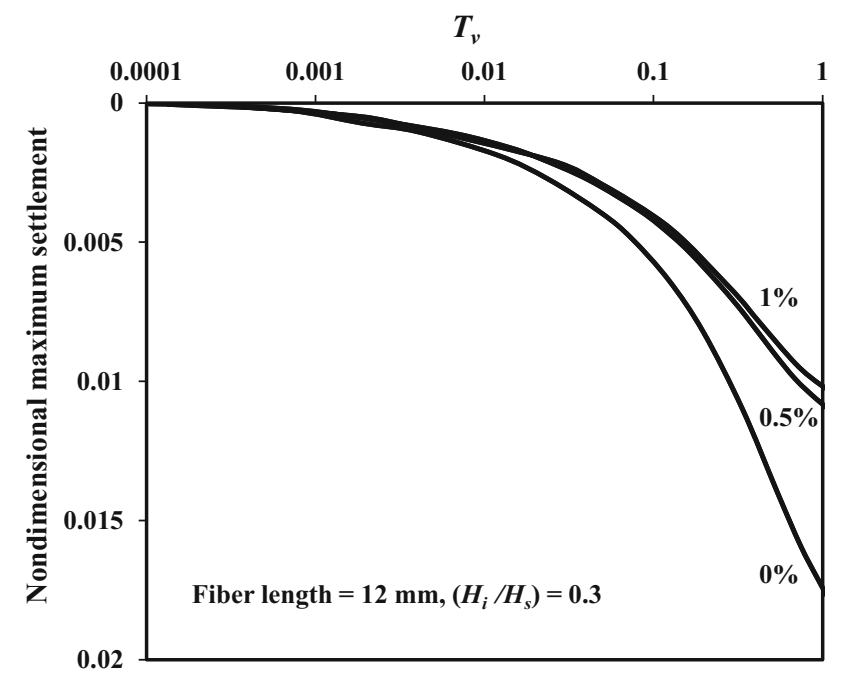

Fig. 10 Effect of $T_{v}$ on settlement response (effect of fiber percentage)

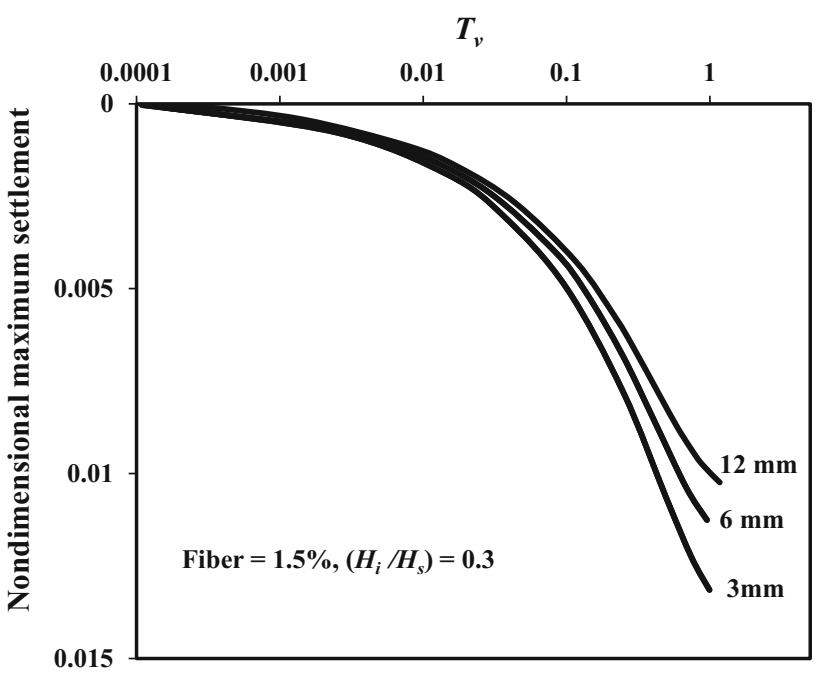

Fig. 11 Effect of $T_{v}$ on settlement response (effect of length of fiber)

the settlement values also increases for different fiber percentages and lengths.

Figure 12 shows the effect of thickness of improved subgrade on settlement response for different time factor values. It is observed that for lower value of $T_{v u}$ (where $T_{v u}$ is the time factor for unimproved subgrade under $H_{i} /$ $H_{s}=0$. However, time factor for the other $H_{i} / H_{s}$ values changes at a particular time period due to the change in $c_{v}$ ) i.e. initial stage of consolidation, almost same amount of settlement is observed for any thickness of the fiber-improved subgrade. However, as the time factor increases settlement reduction is observed due to increase in the thickness of the improved zone. This is due to the fact that

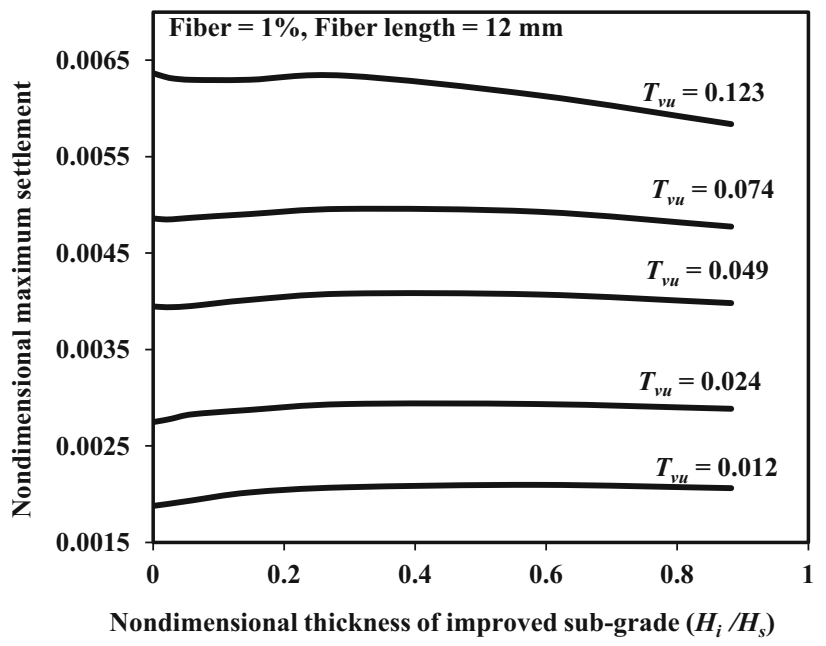

Fig. 12 Effect of thickness of improved sub-grade on settlement response (note: $T_{v u}$ is the time factor for unimproved gub-grade, i.e. $\left.H_{i} / H_{s}=0\right)$ 
as the thickness of the improved zone increases the stiffness as well as rate of consolidation of the subgrade increase. Thus, during consolidation period due to the faster consolidation rate more settlement can be achieved as the thickness of the improved subgrade increases. On the other hand due to increase of thickness, the stiffness of the subgrade also increases and ultimately less amount of settlement is occurred. In case of smaller thickness of the improve zone due to lower stiffness value more settlement can be occurred, but due to lower rate of consolidation during consolidation period less consolidation is achieved. Thus, during initial consolidation period, in case of lower thickness of improved zone lower amount of consolidation is achieved for a particular time and higher settlement is occurred, whereas, in case of higher thickness of the improved zone lower settlement is occurred and higher consolidation is achieved. Because of this reason, in case of initial consolidation period for different thickness of the improved subgrade overall similar amount of settlement is observed. However, as the time of consolidation increases for higher thickness of the improved subgrade consolidation is completed at a faster rate as compared to the lower thickness of improved subgrade. Thus, in a particular time period, the consolidation may be in progress in case of lower thickness of improved subgrade, but it may be completed in case of higher thickness of the improved zone. As the final settlement of the improved zone is less as compared to the unimproved zone, the more settlement difference is observed as the thickness of the improved subgrade increasers. Similar explanation can be given for the observed results as shown in Figs. 10 and 11.

\section{Conclusions}

From the observed results the following conclusions can be made:

- As the fiber content and length increase the elastic modulus value and unconfined compressive strength value increase. However, the rate of increment of unconfined compressive strength value is more as compared to the rate of increment of elastic modulus value. The increment of UCS value from unimproved soil to fiber-reinforced soil with $1 \% 12 \mathrm{~mm}$ fiber is almost 7 times, whereas the increment is $91 \%$ in case of $E$ value.

- Coefficient of Consolidation increases up to $1 \%$ fiber content and beyond that value it becomes constant. With respect to the strength and compressibility, $0.5-1 \%$ fiber content is the optimum value depending on the length of the fiber for the selected soil.
- As the thickness of the improved subgrade increases settlement also decreases in a decreasing rate. Up to $H_{i /} H_{s}=0.3$, the rate of reduction in settlement is more and after that it decreases.

- At initial stage of consolidation, the variation in settlement for different fiber percentages and lengths is negligible. Similarly, during initial stage of consolidation, almost similar amount of settlement is observed for any thickness of the fiber-improved subgrade. However, as the time increases settlement reduction is observed due to increase in the thickness of the fiber-improved zone.

Acknowledgments The authors acknowledge the opportunity to present the research work that forms the basis of this article at the 3rd Conference of the Transportation Research Group of India held at Kolkata (India) from 17 to 20 December, 2015.

\section{References}

1. Maher MH, Ho YC (1994) Mechanical properties of kaolinite/fiber soil composite. J Geotech Eng 120:1381-1393

2. Kumar A, Walia BS, Mohan J (2006) Compressive strength of fiber reinforced highly compressible clay. Constr Build Mater 20:1063-1068

3. Tang C, Shi B, Gao W, Chen F, Cai Y (2007) Strength and mechanical behavior of short polypropylene fiber reinforced and cement stabilized clayey soil. Geotext Geomembr 25:194-202

4. Pradhan PK, Kar RK, Naik A (2012) Effect of random inclusion of polypropylene fibers on strength characteristics of cohesive soil. Geotech Geol Eng 30:15-25

5. Zaimoglu S, Yetimoglu T (2012) Strength behavior of fine grained soil reinforced with randomly distributed polypropylene fibers. Geotech Geol Eng 30:197-203

6. Abdi MR, Parsapajouh A, Arjomand MA (2008) Effects of random fiber inclusion on consolidation, hydraulic conductivity, swelling, shrinkage limit and desiccation cracking of clays. Int $\mathbf{J}$ Civ Eng 6:284-292

7. Kar RK, Pradhan PK (2012) Consolidation characteristics of fiber reinforced cohesive soil. EJGE 12:3861-3874

8. Yetimoglu T, Inanir M, Inanir OE (2005) A study on bearing capacity of randomly distributed fiber-reinforced sand fills overlying soft clay. Geotext Geomembr 23:174-183

9. Chandra S, Viladkar MN, Nagrale PP (2008) Mechanistic approach for fiber-reinforced flexible pavements. J Transp Eng $134: 15-23$

10. Kumar P, Singh SP (2008) Fiber-reinforced fly ash subbases in rural roads. J Transp Eng 134:171-180

11. Deb K, Chandra S, Basudhar PK (2005) Settlement response of a multi layer geosynthetic-reinforced granular fill-soft soil system. Geosynth Int 12:288-298

12. Deb K, Chandra S, Basudhar PK (2007) Nonlinear analysis of multi layer extensible geosynthetic-reinforced granular bed on soft soil. Geotech Geol Eng Int J 25:11-23

13. Deb K, Sivakugan N, Chandra S, Basudhar PK (2007) Numerical analysis of multi layer geosynthetic-reinforced granular bed over soft fill. Geotech Geol Eng Int J 25:639-646

14. Madhav MR, Poorooshasb HB (1988) A new model for geosynthetic-reinforced soil. Comput Geotech 6:277-290 
15. Shukla SK, Chandra S (1995) Modeling of geosynthetic-reinforced engineered granular fill on soft soil. Geosynth Int 2:603-617

16. Yin JH (1997) Modeling geosynthetic-reinforced granular fills over soft soil. Geosynth Int 4:165-185

17. Nogami T, Yong TY (2003) Load-settlement analysis of geosynthetic-reinforced soil with a simplified model. Soils Found 43:33-42

18. Rajesh S, Choudhary K, Chandra S (2015) A generalised model for geosynthetic reinforced railway tracks resting on soft clays. Int J Numer Anal Methods Geomech 39:310-326
19. Deb K (2008) Modeling of granular bed-stone column-improved soft soil. Int J Numer Anal Methods Geomech 32:1267-1288

20. Ghosh C, Madhav MR (1994) Settlement response of a reinforced shallow earth bed. Geotext Geomembr 13:643-656

21. Giroud JP, Noiray L (1981) Geotextile-reinforced unpaved road design. J Geotech Eng Div ASCE 107:1233-1254 